\title{
ДИНАМИКА РОСТА В ОНТОГЕНЕЗЕ ЛИСТЬЕВ ЛИПЫ ОКОЛО АВТОМОБИЛЬНОЙ ДОРОГИ (C) 2015
}

\author{
А.И. Кудряшова, магистрант 3Ум-21
}

направления 120700.68 «Землеустройство и кадастры», ФГБОУ ВПО «Поволжский государственный технологический университет», Йошкар-Ола (Россия), Little-one7@yandex.ru

Введение. Предлагаемое техническое решение может быть использовано при экологическом и технологическом мониторинге за молодыми древесными растениями около автомобильных трасс с интенсивным движением.

Сущность заключается в том, что от середины корневой шейки до примерного центра каждой из четырех локальных зон рулеткой измеряют расстояние от вертикальной оси ствола дерева в середине корневой шейки, а также миллиметровой линейкой высоты у группы учетных листьев от почвы [1-5].

Положительный эффект заключается в том, что впервые точно можно выявлять закономерности динамики поведения за весь цикл онтогенеза по измеренным 20 учетным листам по всему дереву липы, а также по четырем группам листьев в разных локальных зонах по сторонам света по максимальным значениям параметров учетных листьев.

Статистическим моделированием идентифицируются закономерности в виде структур $a=f(t), b=f(t), P=f(t)$ и $S=f(t)$, у которых имеются два нуля - в начале и в конце цикла онтогенеза. Для каждой стороны света были выполнено отдельное статистическое моделирование (рис. 1 - север, рис. 2 восток, рис. 3 - юг, рис. 4 - запад).
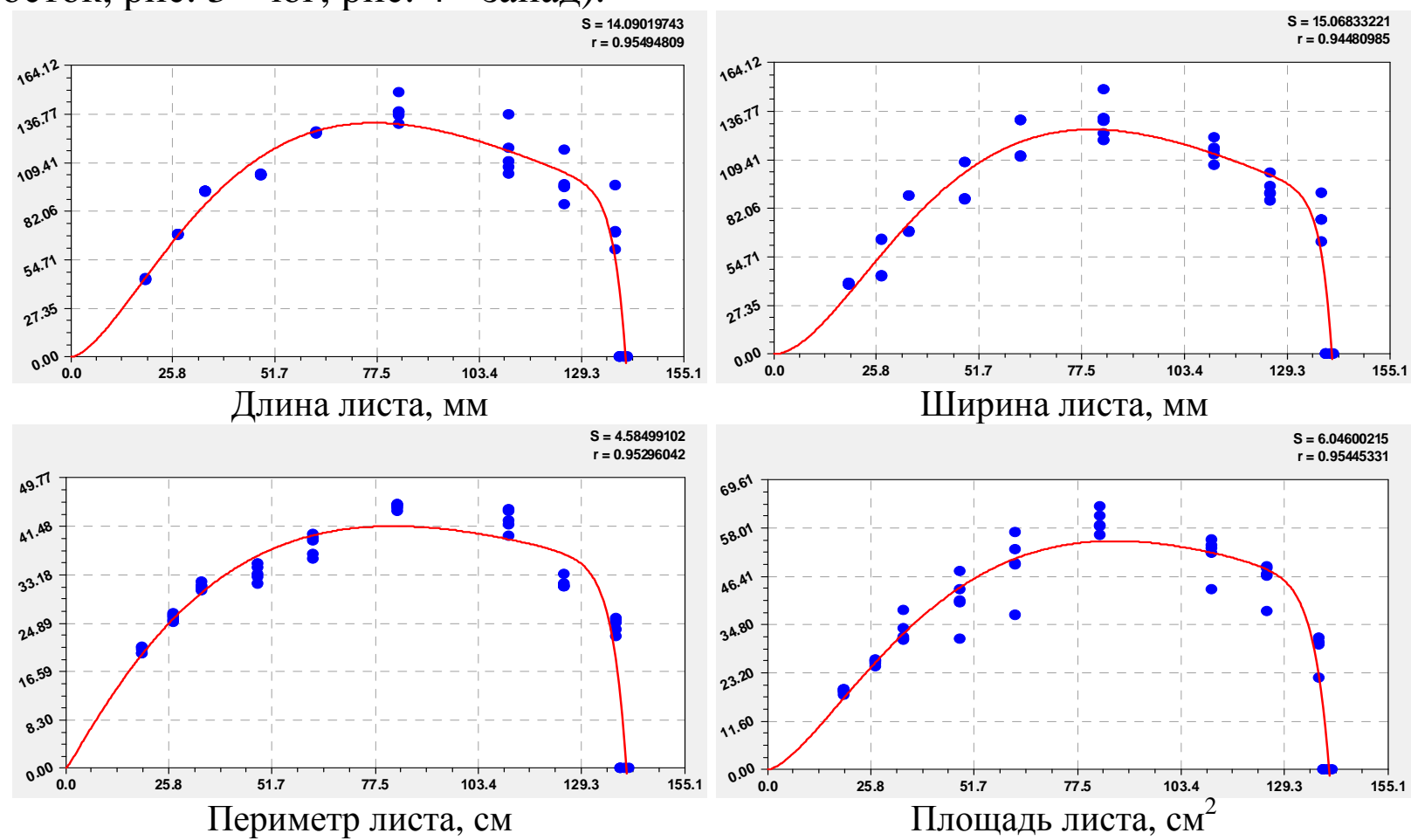

Рисунок 1. Графики закономерности динамики онтогенеза учетных листьев на северной стороне от ствола дерева липы 

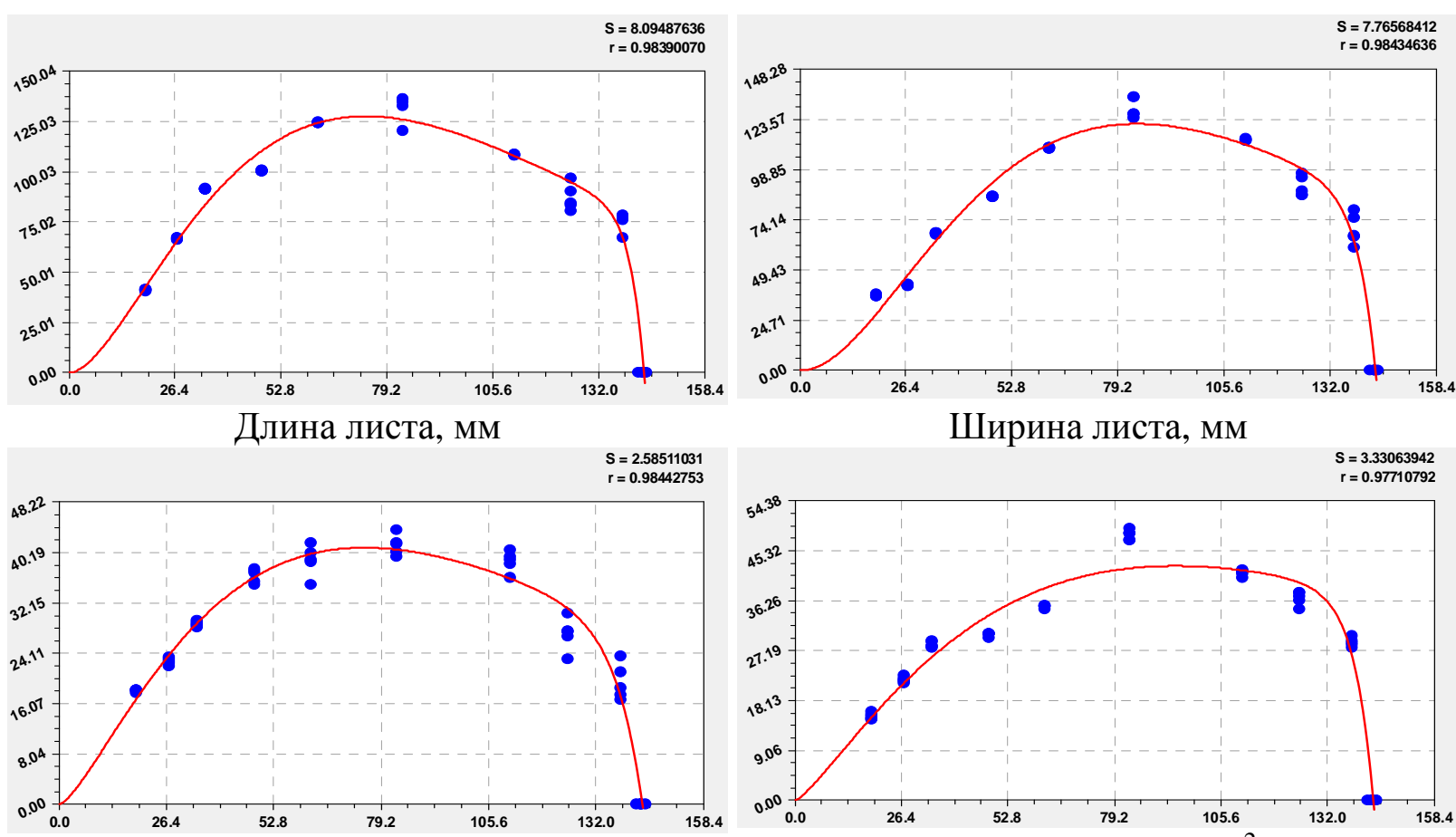

Периметр листа, см

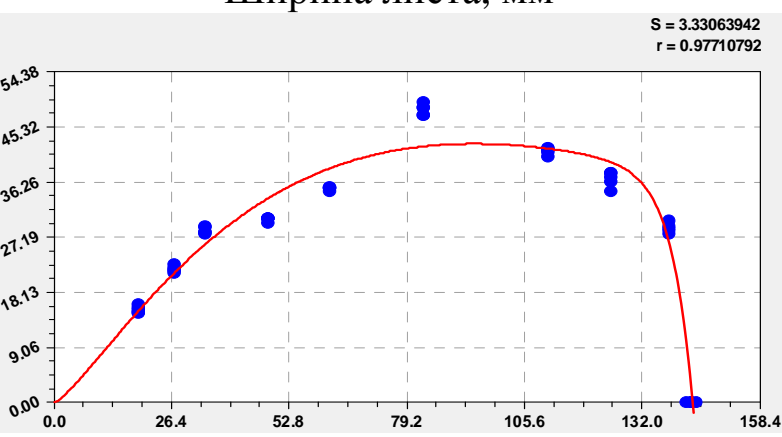

Рисунок 2. Графики закономерности динамики онтогенеза учетных листьев на восточной стороне от ствола дерева липы
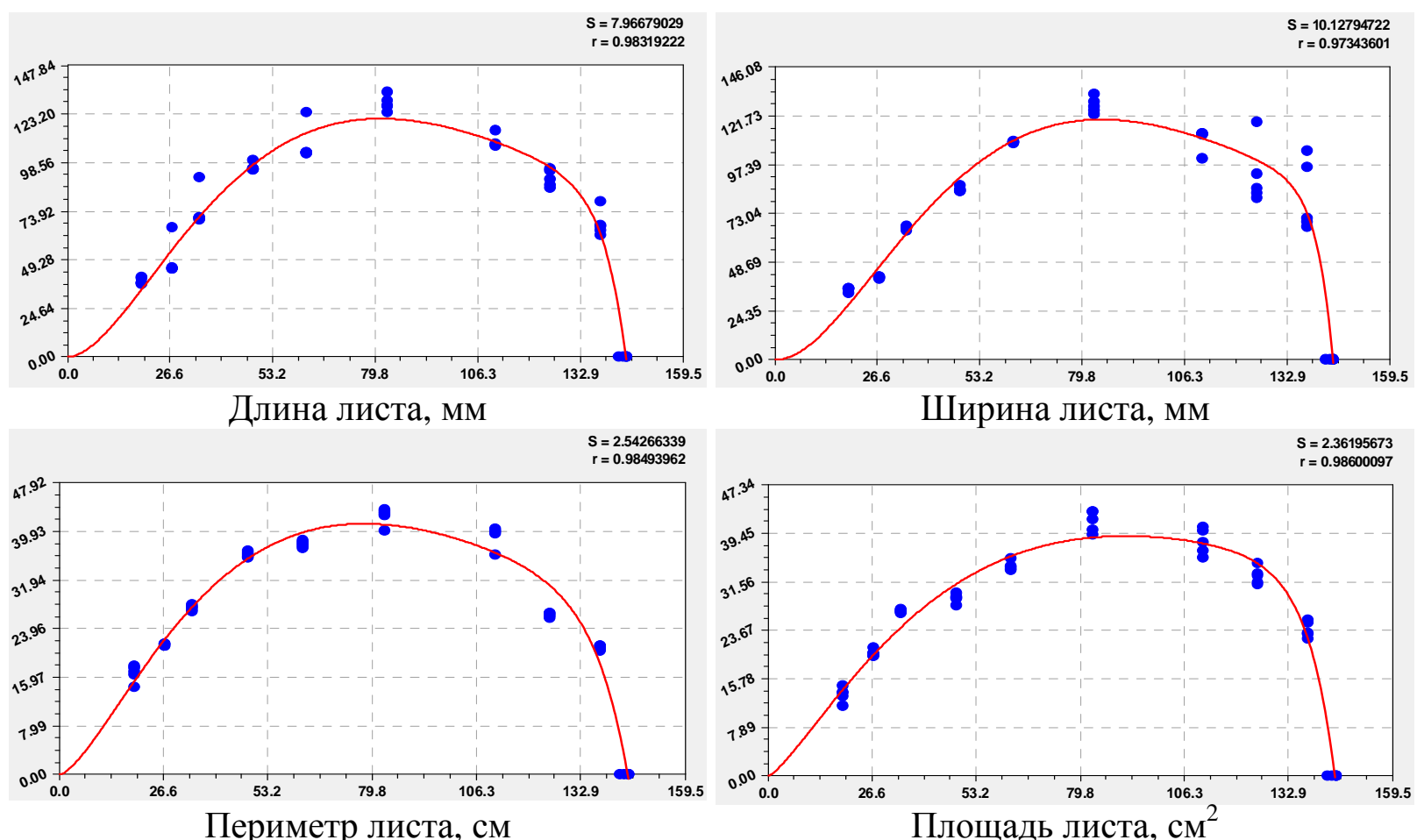

Рисунок 3. Графики закономерности динамики онтогенеза учетных листьев на южной стороне от ствола дерева липы

Отдельно была получена среднестатистическая закономерность для всех 20 учетных листьев по всем четырем сторонам света (рис. 5). Графики показывают, что около дороги стороны света мало влияют на онтогенез учетных листьев. Только периметр и площадь учетного листа при времени вегетации 83 сутки резко отличаются друг друга. Но затем снова разброс точек снижается. 

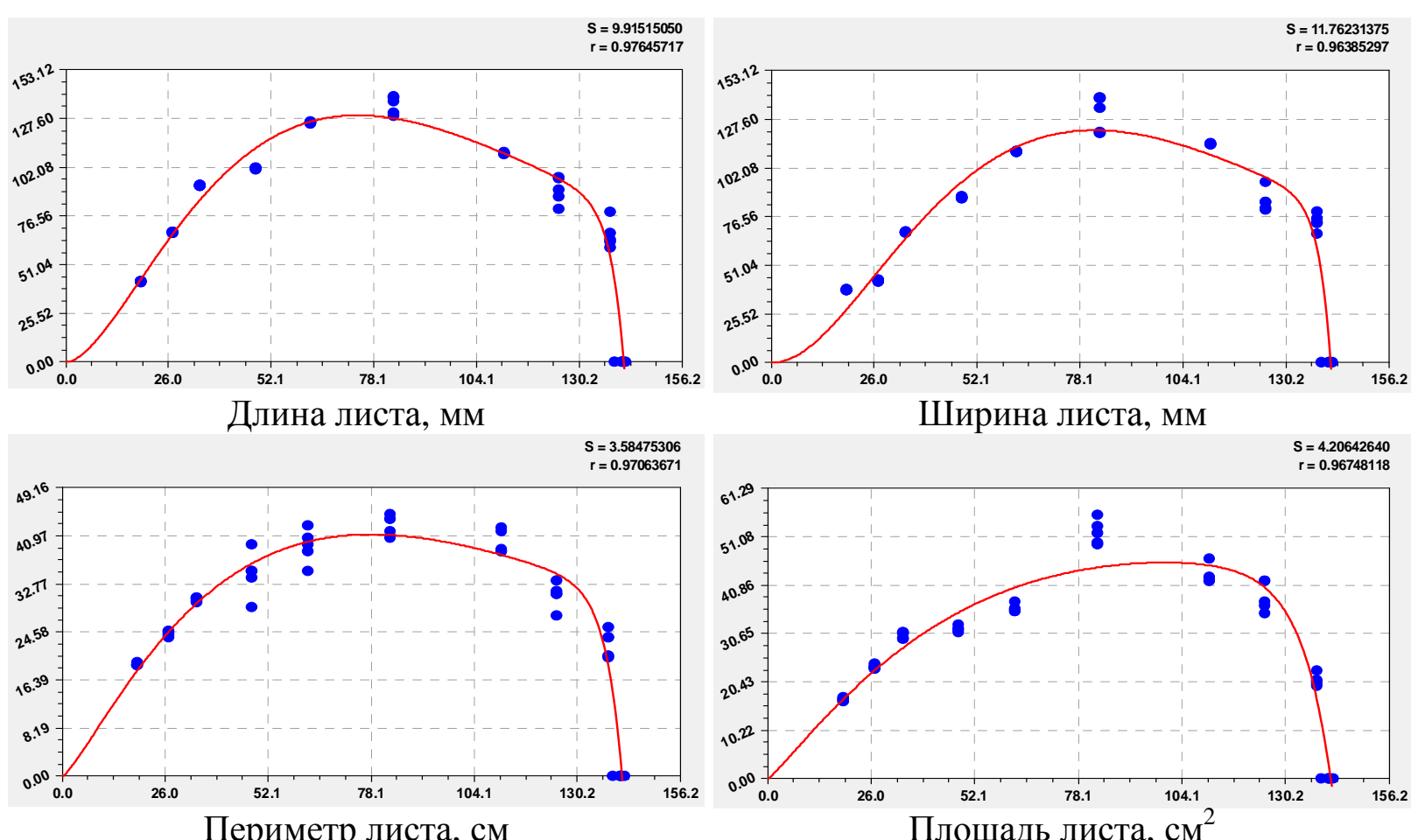

Рисунок 4. Графики закономерности динамики онтогенеза учетных листьев на западной стороне от ствола дерева липы
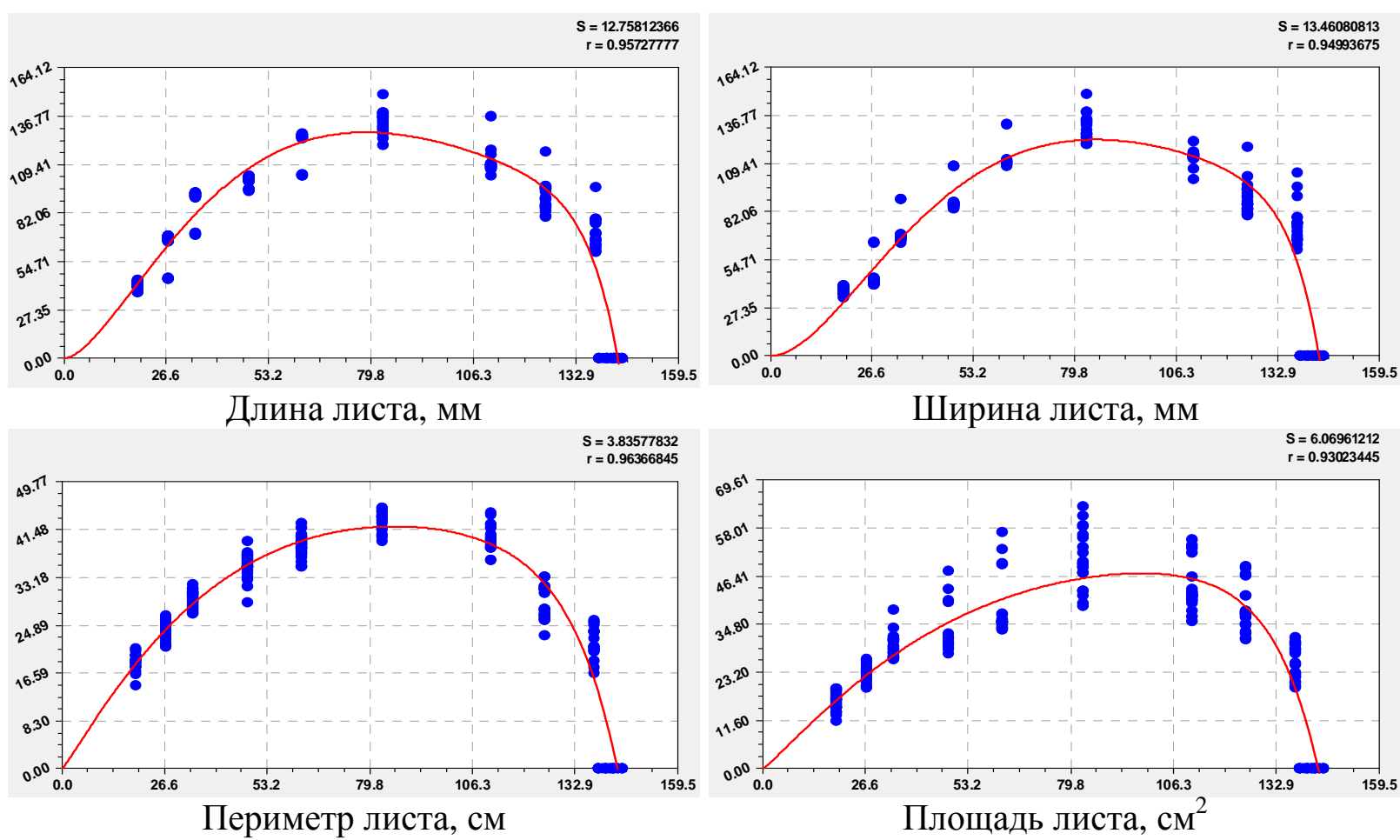

Рисунок 5. Графики закономерности динамики онтогенеза по всем 20 учетным листьям на дереве липы

Далее покажем закономерности среднестатистической динамики четырех основных параметров по сторонам света и у 20 учетных листьев.

Общая закономерность онтогенеза. Онтогенез листьев липы в загрязненной воздушной среде от начала одновременного распускания почек до опадения листа проходит по биотехнической закономерности вида 


$$
y=a_{1} t^{a_{2}} \exp \left(-a_{3} t\right)-a_{4} \exp \left(a_{5} t\right),
$$

где $y$ - показатель, как один из параметров листа (длина, ширина, периметр, площадь),

$t$ - вегетационное время с начала онтогенеза с момента одновременного распускания почек до опадения у всех листьев дерева, сутки,

$a_{1} t^{a_{2}} \exp \left(-a_{3} t\right)$ - биотехнический закон динамики параметров листьев в онтогенезе растения в цикле вегетационного периода от распускания почек до опадения листьев,

$-a_{4} \exp \left(a_{5} t\right)$ - негативное влияние (торможение из-за отрицательного знака с ускорением) развитию и росту листьев от влияния загрязненной воздушной среды по закону экспоненциального роста,

$a_{1} \ldots a_{5}$ - параметры модели (1), конкретные числовые значения которых получают в ходе идентификации биотехнической закономерности в программной среде типа CurveExpert по данным измерений параметров учетных листьев.

В таблице 1 приведены значения параметров модели (1).

Таблица 1

Параметры среднестатистической динамики онтогенеза листьев липы

\begin{tabular}{|c|c|c|c|c|c|c|c|}
\hline \multirow{2}{*}{$\begin{array}{c}\text { Сторона } \\
\text { света }\end{array}$} & \multirow{2}{*}{$\begin{array}{c}\text { Параметр } \\
\text { листа липы }\end{array}$} & \multicolumn{5}{|c|}{ Закономерность $y=a_{1} t^{a_{2}} \exp \left(-a_{3} t\right)-a_{4} \exp \left(a_{5} t\right)$} & \multirow{2}{*}{$\begin{array}{l}\text { Коэфф. } \\
\text { коррел. }\end{array}$} \\
\hline & & $a_{1}$ & $a_{1}$ & $a_{1}$ & $a_{1}$ & $a_{1}$ & \\
\hline \multirow{4}{*}{$\begin{array}{l}\text { Север } \\
5 \text { шт. } \\
\text { Рис. } 1\end{array}$} & & 515 & & 216 & 1,32229 & 8 & \\
\hline & & & & & & & \\
\hline & Пери & & 4 & & & & \\
\hline & & & & & & & \\
\hline \multirow{4}{*}{$\begin{array}{c}\text { Восток } \\
5 \text { шт. } \\
\text { Рис. } 2\end{array}$} & & & & & & & \\
\hline & & & & & & & \\
\hline & Пе & & & & & & \\
\hline & & & & & & & \\
\hline \multirow{4}{*}{$\begin{array}{c}\text { Юг } \\
5 \text { шт. } \\
\text { Рис. } 3\end{array}$} & & & & & & & \\
\hline & & & 17 & & 4,4 & 08 & \\
\hline & & & & & & & \\
\hline & & & & & & & \\
\hline \multirow{4}{*}{$\begin{array}{l}\text { Запад } \\
5 \text { шт. } \\
\text { Рис. } 4\end{array}$} & & & & & & & \\
\hline & & & & & & & \\
\hline & $\Pi \epsilon$ & & & & & 79 & \\
\hline & & & & & & & \\
\hline \multirow{4}{*}{$\begin{array}{c}\text { Липа } \\
20 \text { шт. } \\
\text { Рис. } 5\end{array}$} & & & & & & & \\
\hline & & & 2933 & & & & \\
\hline & & & & & & & \\
\hline & Площадь $S, \mathrm{~cm}^{2}$ & 0,71427 & 1,13084 & 0,0099777 & 0,00016403 & 0,087477 & 0,9302 \\
\hline
\end{tabular}

Bсе 20 учетных листьев липы дают биотехнические закономерности (1) с конкретными значениями параметров модели с коэффициентами корреляции от 0,9302 до 0,9637. Поэтому уровень тесноты факторной связи превышает 0,9 (сильнейшая связь). При этом по отдельным направлениям сторон света: север - от 0,9448 до 0,9549; восток - от 0,9771 до 0,9844; юг - от 0,9734 до 0,9860; за- 
пад - от 0,9639 до 0,9765 .

Наибольшую тесноту факторной связи имеет:

- на север длина $a$, мм $(0,9549)$;

- на восток периметр $P$, см $(0,9844)$;

- на юг площадь $S$, см$^{2}(0,9860)$;

- на запад длина $a$, мм $(0,9765)$;

- целиком без учета сторон света площадь $S, \mathrm{~cm}^{2}$.

Группы учетных листьев. По результатам статистического моделирования в таблице 2 приведены параметры моделей (по данным табл. 1) с дополнением трех внешних факторов: расстояния от дороги, высоты листа над поверхностью почвы и среднего значения вегетационного периода для 5 учетных листьев и всех 20 учетных листьев липы.

Таблица 2

Исходные данные параметров модели групп листьев загрязненной липы

\begin{tabular}{|c|c|c|c|c|c|c|c|c|c|}
\hline \multirow{2}{*}{$\begin{array}{l}\text { Азимут } \\
\varphi, \text { град }\end{array}$} & \multirow{2}{*}{$\begin{array}{c}\text { Расстояние } \\
\text { от дороги } \\
L, \text { м }\end{array}$} & \multirow{2}{*}{\begin{tabular}{|c|} 
Высота \\
листа \\
$\bar{H}$, см \\
\end{tabular}} & \multirow{2}{*}{$\begin{array}{c}\text { Вегетац. } \\
\text { период } \\
\bar{T}, \text { сут. }\end{array}$} & \multicolumn{6}{|c|}{ Параметры статистической модели } \\
\hline & & & & $a_{1}$ & $a_{2}$ & $a_{3}$ & $a_{4}$ & $a_{5}$ & $r$ \\
\hline \multicolumn{10}{|c|}{ Длина листа, мм } \\
\hline $\mathrm{C}$ & 5,0 & 146 & 139,6 & 0,51552 & 1.66050 & 0,021666 & $1,32229 \mathrm{e}-19$ & 0,34179 & 0,9549 \\
\hline $\mathrm{B}$ & 3,2 & 154 & 143,0 & 0,37322 & 1,76691 & 0,023911 & $2,31183 \mathrm{e}-17$ & 0,29784 & 0,9839 \\
\hline Ю & 3,9 & 159 & 144,4 & 0,22874 & 1,84679 & 0,022789 & $8,26384 \mathrm{e}-10$ & 0,17510 & 0,9832 \\
\hline 3 & 5,8 & 154 & 140,8 & 0,38283 & 1,76296 & 0,023857 & $3,39479 \mathrm{e}-17$ & 0,29938 & 0,9765 \\
\hline 20 шт. & 4,5 & 153 & 142,0 & 0,44933 & 1,68192 & 0,021515 & $2,73458 \mathrm{e}-7$ & 0,13630 & 0,9573 \\
\hline \multicolumn{10}{|c|}{ Ширина листа, мм } \\
\hline $\mathrm{C}$ & 5,0 & 146 & 139,6 & 0,18940 & 1,92406 & 0,024081 & $2,86047 \mathrm{e}-21$ & \begin{tabular}{|l|}
0,36877 \\
\end{tabular} & 0,9448 \\
\hline $\mathrm{B}$ & 3,2 & 154 & 143,0 & 0,10479 & 2,05697 & 0,024503 & $1,08933 \mathrm{e}-12$ & 0,22336 & 0,9843 \\
\hline Ю & 3,9 & 159 & 144,4 & 0,10375 & 2,05117 & 0,024226 & $4,48564 \mathrm{e}-14$ & 0,24308 & 0,9734 \\
\hline 3 & 5,8 & 154 & 140,8 & 0,087434 & 2,12835 & 0,026079 & $1,92837 \mathrm{e}-19$ & 0,33604 & 0,9639 \\
\hline 20 шт. & 4,5 & 153 & 142,0 & 0,15969 & 1,92933 & 0,022627 & $2,59118 \mathrm{e}-7$ & 0,13686 & 0,9499 \\
\hline \multicolumn{10}{|c|}{ Периметр листа, см } \\
\hline $\mathrm{C}$ & 5,0 & 146 & 139,6 & 1,01147 & 1,09091 & 0,013325 & $8,17102 \mathrm{e}-17$ & 0,28910 & 0,9530 \\
\hline $\mathrm{B}$ & 3,2 & 154 & 143,0 & 0,37532 & 1,41475 & 0,018865 & $6,00308 \mathrm{e}-9$ & 0,15544 & 0,9844 \\
\hline Ю & 3,9 & 159 & 144,4 & 0,25404 & 1,51870 & 0,019573 & $6,83352 \mathrm{e}-7$ & 0,12120 & 0,9849 \\
\hline 3 & 5,8 & 154 & 140,8 & 0,61047 & 1,25514 & 0,016096 & $1,26268 \mathrm{e}-14$ & 0,25079 & 0,9706 \\
\hline 20 шт. & 4,5 & 153 & 142,0 & 0,89977 & 1,09934 & 0,012152 & 0,00023822 & 0,083096 & 0,9637 \\
\hline \multicolumn{10}{|c|}{ Площадь листа, см² } \\
\hline $\mathrm{C}$ & 5,0 & 146 & 139,6 & 0,23255 & 1,57858 & 0,018218 & $2,18465 \mathrm{e}-15$ & \begin{tabular}{|l|}
0,26759 \\
\end{tabular} & 0,9545 \\
\hline $\mathrm{B}$ & 3,2 & 154 & 143,0 & 0,44743 & 1,28489 & 0,013636 & $1,06970 \mathrm{e}-12$ & 0,21774 & 0,9771 \\
\hline Ю & 3,9 & 159 & 144,4 & 0,38409 & 1,31408 & 0,014345 & $1,79069 \mathrm{e}-8$ & \begin{tabular}{|l|}
0,14754 \\
\end{tabular} & 0,9860 \\
\hline 3 & 5,8 & 154 & 140,8 & 0,72916 & 1,13720 & 0,010970 & $1,89888 \mathrm{e}-7$ & 0,13603 & 0,9675 \\
\hline 20 шт. & 4,5 & 153 & 142,0 & 0,71427 & 1,13084 & 0,0099777 & 0,00016403 & 0,087477 & 0,9302 \\
\hline
\end{tabular}

Однако из-за малой численности значений внешних факторов статистическое моделирование их влияния на параметры модели не проводим.

Факторный анализ параметров учетных листьев. В таблице 3 даны максимальные значения параметров по каждому учетному листу. Эти максимальные значения для загрязненной липы проявились в один день 27.08.2014 через 83 сутки от начала вегетации 02.05.2014 по распусканию почек (табл. 4). 
Таблица 3

Исходные данные параметров листьев загрязненной липы

\begin{tabular}{|c|c|c|c|c|c|c|c|c|c|}
\hline \multirow{2}{*}{$\begin{array}{c}\text { № } \\
\text { листа }\end{array}$} & \multirow{2}{*}{$\begin{array}{l}\text { Ази- } \\
\text { мут }\end{array}$} & \multirow{2}{*}{$\begin{array}{c}\text { Расстояние } \\
\text { от дороги } \\
L, \text { м }\end{array}$} & \multirow{2}{*}{$\begin{array}{c}\text { Высота } \\
\text { листа } \\
H, \text { см } \\
\end{array}$} & \multirow{2}{*}{$\begin{array}{c}\text { Вегетац. } \\
\text { период } \\
T \text {, сут. }\end{array}$} & \multicolumn{5}{|c|}{ Максимальные параметры листа } \\
\hline & & & & & $t^{*}$, сут. & $a_{\max }, \mathrm{MM}$ & $b_{\max }, \mathrm{MM}$ & $P_{\max }, \mathrm{cm}$ & $S_{\max }, \mathrm{cm}^{2}$ \\
\hline 1 & \multirow{5}{*}{$\mathrm{C}$} & 5,0 & 146 & 140 & 83 & 138.4 & 133.2 & 44.69 & 56.48 \\
\hline 2 & & 5,0 & 146 & 139 & 83 & 136.4 & 120.4 & 44.12 & 58.48 \\
\hline 3 & & 5,0 & 146 & 141 & 83 & 138.0 & 124.4 & 44.97 & 58.7 \\
\hline 4 & & 5,0 & 146 & 139 & 83 & 131.2 & 131.6 & 45.25 & 60.96 \\
\hline 5 & & 5,0 & 146 & 139 & 83 & 149.2 & 149.2 & 45.25 & 63.28 \\
\hline 6 & \multirow{5}{*}{ B } & 3,2 & 154 & 144 & 83 & 136.4 & 134.8 & 41.58 & 47.26 \\
\hline 7 & & 3,2 & 154 & 143 & 83 & 135.2 & 134.8 & 39.60 & 47.32 \\
\hline 8 & & 3,2 & 154 & 143 & 83 & 136.4 & 124.4 & 43.84 & 48.62 \\
\hline 9 & & 3,2 & 154 & 142 & 83 & 133.2 & 126.4 & 40.45 & 48.62 \\
\hline 10 & & 3,2 & 154 & 143 & $62 / 83$ & 125.0 & 126.8 & 41.86 & 49.44 \\
\hline 11 & \multirow{5}{*}{ Ю } & 3,9 & 159 & 145 & 83 & 124.4 & 122.8 & 42.71 & 39.38 \\
\hline 12 & & 3,9 & 159 & 145 & 83 & 127.2 & 124.8 & 42.99 & 40.04 \\
\hline 13 & & 3,9 & 159 & 144 & 83 & 127.6 & 126.8 & 43.27 & 41.82 \\
\hline 14 & & 3,9 & 159 & 145 & 83 & 130.0 & 128.8 & 43.56 & 43,68 \\
\hline 15 & & 3,9 & 159 & 143 & 83 & 134.4 & 132.8 & 40.16 & 43.04 \\
\hline 16 & \multirow{5}{*}{3} & 5,8 & 154 & 141 & 83 & 136.8 & 121.2 & 40.73 & 49.56 \\
\hline 17 & & 5,8 & 154 & 142 & 83 & 138.8 & 139.2 & 43.84 & 49.94 \\
\hline 18 & & 5,8 & 154 & 141 & 83 & 129.2 & 133.6 & 41.86 & 52.00 \\
\hline 19 & & 5,8 & 154 & 141 & 83 & 139.2 & 120.8 & 43.84 & 53.42 \\
\hline 20 & & 5,8 & 154 & 139 & 83 & 130.8 & 138.8 & 44.69 & 55.72 \\
\hline
\end{tabular}

Таблица 4

Ранговые распределения параметров учетных листьев загрязненной липы

\begin{tabular}{|c|c|c|c|c|c|c|c|c|c|c|}
\hline $\begin{array}{c}\text { № } \\
\text { листа }\end{array}$ & $R_{T}$ & $\begin{array}{c}\text { Вег. период } \\
T, \text { сут. }\end{array}$ & $R_{a}$ & $\begin{array}{c}\text { Длина } \\
a_{\max }, \mathrm{Mм}\end{array}$ & $R_{b}$ & $\begin{array}{l}\text { Ширина } \\
b_{\max }, \text { мм }\end{array}$ & $R_{P}$ & $\begin{array}{c}\text { Периметр } \\
P_{\max }, \text { см }\end{array}$ & $R_{S}$ & $\begin{array}{c}\text { Площадь } \\
S_{\max }, \mathrm{cm}^{2}\end{array}$ \\
\hline 1 & 15 & 140 & 3 & 138.4 & 6 & 133.2 & 3 & 44.69 & 4 & 56.48 \\
\hline 2 & 16 & 139 & 6 & 136.4 & 19 & 120.4 & 5 & 44.12 & 3 & 58.48 \\
\hline 3 & 11 & 141 & 4 & 138.0 & 14 & 124.4 & 2 & 44.97 & 2 & 58.7 \\
\hline 4 & 16 & 139 & 12 & 131.2 & 8 & 131.6 & 0 & 45.25 & 1 & 60.96 \\
\hline 5 & 16 & 139 & 0 & 149.2 & 0 & 149.2 & 0 & 45.25 & 0 & 63.28 \\
\hline 6 & 3 & 144 & 6 & 136.4 & 3 & 134.8 & 15 & 41.58 & 14 & 47.26 \\
\hline 7 & 5 & 143 & 9 & 135.2 & 3 & 134.8 & 19 & 39.60 & 13 & 47.32 \\
\hline 8 & 5 & 143 & 6 & 136.4 & 14 & 124.4 & 6 & 43.84 & 11 & 48.62 \\
\hline 9 & 9 & 142 & 11 & 133.2 & 12 & 126.4 & 17 & 40.45 & 11 & 48.62 \\
\hline 10 & 5 & 143 & 18 & 125.0 & 10 & 126.8 & 13 & 41.86 & 10 & 49.44 \\
\hline 11 & 0 & 145 & 19 & 124.4 & 16 & 122.8 & 12 & 42.71 & 19 & 39.38 \\
\hline 12 & 0 & 145 & 17 & 127.2 & 13 & 124.8 & 11 & 42.99 & 18 & 40.04 \\
\hline 13 & 3 & 144 & 16 & 127.6 & 10 & 126.8 & 10 & 43.27 & 17 & 41.82 \\
\hline 14 & 0 & 145 & 14 & 130 & 9 & 128.8 & 9 & 43.56 & 15 & 43.68 \\
\hline 15 & 5 & 143 & 10 & 134.4 & 7 & 132.8 & 18 & 40.16 & 16 & 43.04 \\
\hline 16 & 11 & 141 & 5 & 136.8 & 17 & 121.2 & 16 & 40.73 & 9 & 49.56 \\
\hline 17 & 9 & 142 & 2 & 138.8 & 1 & 139.2 & 6 & 43.84 & 8 & 49.94 \\
\hline 18 & 11 & 141 & 15 & 129.2 & 5 & 133.6 & 13 & 41.86 & 7 & 52.00 \\
\hline 19 & 11 & 141 & 1 & 139.2 & 18 & 120.8 & 6 & 43.84 & 6 & 53.42 \\
\hline 20 & 16 & 139 & 13 & 130.8 & 2 & 138.8 & 3 & 44.69 & 5 & 55.72 \\
\hline
\end{tabular}


Однако учетный лист № 10 получил максимум длины через 62 сутки, а остальные три параметра - через 83 сутки.

Этот факт указывает на то, что при уточнении методики для повышения точности измерений можно будет определять точнее даты максимума каждого из четырех параметров учетного листа.

У любых факторов имеется четкая векторная ориентация. Любой человек понимает направленность количественных изменений в сельском хозяйстве.

Каждый человек стремится к лучшему в жизни, поэтому возможны всего два варианта векторов поведения:

a) лучше меньше (да лучше, символ $\downarrow$ по вектору «лучше $\rightarrow$ хуже»);

б) лучше больше (и это благо для жизнедеятельности листьев липы).

В функции $=$ РАНГ(Т1;T\$1:T\$20;0) для первого показателя $T$ в программной среде Excel приняты следующие условные обозначения: T1 - идентификатор ранжируемого второго столбца и первой строки; Т\$1 - первая строка ранжируемого столбца; Т\$20 - последняя строка ранжируемого столбца по данным таблицы $1 ; 0 \vee 1$ - ранжирование по убыванию (0) или возрастанию (1).

Ранги изменяются от нуля, поэтому придется из результатов ранжирования в программной среде Excel вычитать единицу (см. табл. 4).

Приведение всех показателей к вектору «лучше $\rightarrow$ хуже» дает возможность суммирования всех рангов и по их сумме снова провести рейтинг.

Таблица 5

Ранговые распределения параметров

\begin{tabular}{|r|c|c|c|c|c|c|c|}
\hline № & $R_{T}$ & $R_{a}$ & $R_{b}$ & $R_{P}$ & $R_{S}$ & $\sum R$ & $I_{n}$ \\
\hline 1 & 15 & 3 & 6 & 3 & 4 & 31 & 2 \\
\hline 2 & 16 & 6 & 19 & 5 & 3 & 49 & 9 \\
\hline 3 & 11 & 4 & 14 & 2 & 2 & 33 & 3 \\
\hline 4 & 16 & 12 & 8 & 0 & 1 & 37 & 4 \\
\hline 5 & 16 & 0 & 0 & 0 & 0 & 16 & 1 \\
\hline 6 & 3 & 6 & 3 & 15 & 14 & 41 & 6 \\
\hline 7 & 5 & 9 & 3 & 19 & 13 & 49 & 9 \\
\hline 8 & 5 & 6 & 14 & 6 & 11 & 42 & 7 \\
\hline 9 & 9 & 11 & 12 & 17 & 11 & 60 & 14 \\
\hline 10 & 5 & 18 & 10 & 13 & 10 & 56 & 11 \\
\hline 11 & 0 & 19 & 16 & 12 & 19 & 66 & 15 \\
\hline 12 & 0 & 17 & 13 & 11 & 18 & 59 & 13 \\
\hline 13 & 3 & 16 & 10 & 10 & 17 & 56 & 11 \\
\hline 14 & 0 & 14 & 9 & 9 & 15 & 47 & 8 \\
\hline 15 & 5 & 10 & 7 & 18 & 16 & 56 & 11 \\
\hline 16 & 11 & 5 & 17 & 16 & 9 & 58 & 12 \\
\hline 17 & 9 & 2 & 1 & 6 & 8 & 26 & 1 \\
\hline 18 & 11 & 15 & 5 & 13 & 7 & 51 & 10 \\
\hline 19 & 11 & 1 & 18 & 6 & 6 & 42 & 7 \\
\hline 20 & 16 & 13 & 2 & 3 & 5 & 39 & 5 \\
\hline$\sum R$ & 167 & 187 & 187 & 184 & 189 & 914 & - \\
\hline$I_{y}$ & 1 & 3 & 3 & 2 & 4 & - & - \\
\hline
\end{tabular}

Из данных таблицы 5 видно, что с экологических позиций лучшими годами стали учетные листья № 5, 1 и 3 .

Взаимосвязь фактора от самого себя определяется ранговым распределением, то есть это - монарное отношение. Оно показывает добротность исходных данных и служит для проверки их достоверности и добротности по коэффициенту корреляции $R$ уравнений распределений значений $y=f(R=0,1,2,3, \ldots)$.

Ранги удобно использовать вместо факторов, так как снимают математическую проблему «проклятия размерности», например, при рейтинге показателей.

Таким образом, факторный анализ проводится в четыре этапа:

1) выявление закономерностей рангового распределения;

2) рейтинг строк и столбцов матрицы по данным таблицы 6;

3) выявление закономерностей бинарных отношений;

4) рейтинг бинарных отношений по коэффициенту корреляции. 
Результат эксперимента заключается в том, что за вегетационный период по суткам от начала распускания почек листьев (по дате начала вегетационного периода время $t$ принимается равным нулю для всех не менее 20 учетных листьев) до конца вегетационного периода (в день опадания каждого учетного листа). В периоде онтогенеза каждого учетного листа выполняют фотографирование не менее 10 раз через прозрачную палетку с сеткой 2 мм, а затем за период онтогенеза у каждого учетного листа принимают продолжительность с даты начала распускания почек до даты опадения каждого из учетных листьев.

Преимуществом предлагаемого способа является идентификация динамических рядов измерений среднестатистической динамики роста не менее пяти учетных листьев липы по каждой стороне света и 20 учетных листьев по всему дереву липы. При этом онтогенез листьев липы в загрязненной воздушной среде характеризуется трендом, содержащим всего две составляющие: первая показывает динамику развития и роста листьев по биотехническому закону, а вторая - негативное воздействие на онтогенез учетных листьев загрязнения воздуха по закону экспоненциального роста со временем вегетации листьев.

\section{СПИСОК ЛИТЕРАТУРЫ}

1. Кудряшова А.И. Описательная статистика параметров формы листьев липы // Проблемы рекреационных насаждений, интродукции и сохранения биоразнообразия растительного мира: Матер. Российской научно-практ. конф. с междунар. участием, посв. 25-летию организации Чебоксарского филиала Главного ботанического сада им. Н.В. Цицина РАН. Чебоксары, 2014. С. 27-30.

2. Кудряшова А.И. Анализ онтогенеза листьев липы // Матер. научнопракт. конф. «Математическое моделирование в области клеточной биологии, биохимии и биофизики» 25-26 ноября 2014 г. Тольятти: Тольяттинский ГУ, 2014. С. 137-145.

3. Кудряшова А.И. Способ измерения периметра и площади листа дерева // III Междунар. научно-практ. конф. «Актуальные вопросы науки и хозяйства: новые вызовы и решения». СПб.: Общественная научная организация «Наука и хозяйство». № 3. 2014. С. 17-20.

4. Кудряшова А.И. Способ измерения периметра и площади листа у древесных растений // «Опыт прошлого - взгляд в будущее» - 4-я Международная научно-практическая конференция молодых ученых и студентов. Материалы конференции: ТулГУ, Тула, 2014, С. 372-376.

5. Кудряшова А.И. Измерение периметра и площади листа дерева // Модернизация системы управления объектами недвижимости: сб. научн. тр. I междунар. науч.-практ. конф. 22-23.10.2014 г., Пенза: ПГУАС, 2014. С. 89-95.

\section{DYNAMICS OF GROWTH IN ONTOGENESIS THE LEAVES OF THE LINDEN TREES NEAR THE ROAD (C) 2015}

A.I. Kudryashova, undergraduate ZUm-21 toward 120700.68 "Land management and cadastre", Volga State Technological University, Yoshkar-Ola (Russia), Little-one7@yandex.ru 